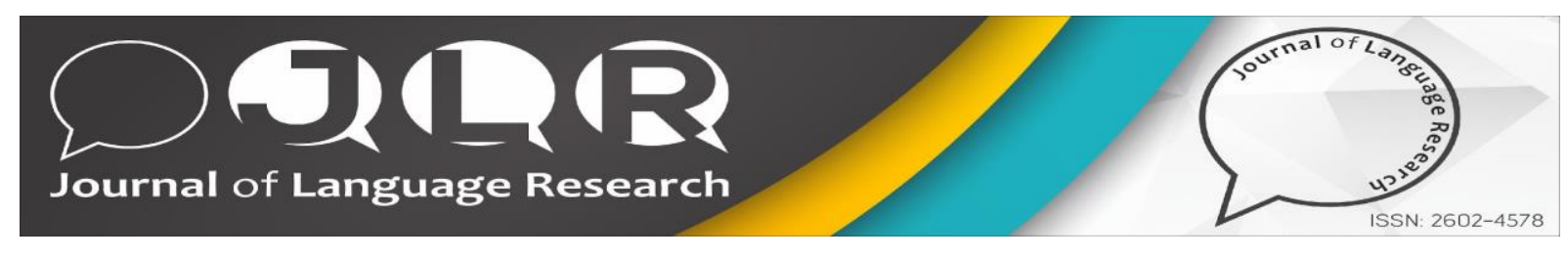

\title{
Emotional Intelligence and Language Teaching
}

Review Article

\author{
Mert Pekbay $^{1}$ (D) , Republic of Turkiye, The Ministry of National Education, \\ mertbau07@gmail.com \\ Onur Karasu2 ${ }^{2}$, Republic of Turkiye, The Ministry of National Education, \\ karasuonurr@gmail.com \\ Oya Tunaboylu ${ }^{3}$ iD , Republic of Turkiye, Suleyman Demirel University, \\ oyatunaboylu@gmail.com
}

Recommended citation: Pekbay, M., Karasu, O., Tunaboylu, O. (2021) Emotional Intelligence and Language Teaching. Journal of Language Research (JLR), 5(1),17-30, DOI: 10.51726/jlr.1034535

\begin{abstract}
This paper reviews Emotional Intelligence (EI) and the development of models which focus on the individual's cognitive and non-cognitive abilities and skills. It also emphasizes the differences and similarities between the mentioned models and the value of EI in educational contexts.
\end{abstract}

Keywords: emotional intelligence, English language teaching, stress, job satisfaction, job performance

\section{INTRODUCTION}

Antoine de Saint-Exupêry, in his worldwide known Novella Little Prince, reflects the role of emotions as: "It is only with the heart that one can see rightly; what is essential is invisible to the eye." Likewise, emotions take an important role in people's lives and reflect behaviors as they are housing deep untold feelings and hidden behaviors. People make judgments through their emotions, which are their reactions to their conditions. Hence, responding to the question "what is emotion?" or, in other words, describing emotion is a much harder job than it looks. Oxford Dictionary defines emotion literally as "a strong feeling deriving from one's circumstances, mood, or relationships with others."

Britannica describes emotion as "a complex experience of consciousness, bodily sensation, and behavior that reflects the personal significance of a thing, an event, or a state of affairs."

According to Hockenbury and Hockenbury (2007), emotion is a complicated state of mind consisting of three distinctive components. The first is subjective experience: several basic universal emotions experienced worldwide to different extents and ways. The second one is physiological response; All people experience any emotion by physically responding to different types of reactions physically such as sweating palms, shaking voices, heart rate beat, and such. The last one is called expressive behavior encompassing verbal, facial, and other nonverbal behaviors used to express our emotions in different circumstances.

Scholars believe each emotion or feeling has a different effect, giving unstated underlying messages. Therefore, emotions have their wisdom concerning this emotional intelligence put forward in the late 1980s by Stanley Greenspan to describe the nature and scope of emotional intelligence.

\footnotetext{
${ }^{1}$ ORCID ID: 0000-0001-6790-933X

${ }^{2}$ ORCID ID: 0000-0002-2739-237X

${ }^{3}$ ORCID ID: 0000-0002-9926-7973

Submitted: 10.12.2021

Accepted: 25.12.2021

https://doi.org/10.51726/jlr.1034535
} 


\section{THE CONCEPT OF EMOTIONAL INTELLIGENCE}

Since the IQ (the intelligence quotient) definition of intelligence was found to be too narrow as it confines the scope of intelligence with the quantification of general ability of a variety of tasks, some scholars tried to explore a more comprehensive definition of human intellectual capability, which is characterized by different complex cognitive traitsSome scholars, for instance, (Extremera \& Berroca, 2006; Matzel \& Sauce, 2017) find it challenging to formulate IQ as human traits are too complex and may vary from one situation to another with no clear-cut boundary ability to define the abstract concept of intelligence. Therefore there was a need to seek inclusive alternative concepts and broader definitions. One of these is Emotional Intelligence (EI) theory, and it was introduced in the 1990s by Goleman, and since then, its concept and scope of definitions have been introduced.

There are controversial opinions regarding the meaning of EI since the concept is developing so fast that researchers continuously modify the way they describe emotion. For instance, Salovey and Mayer (1990) describe emotional intelligence as "the ability to monitor one's own and others' feelings and emotions, to discriminate among them and to use this information to guide one's thinking and actions."

Faltas (2017), though, depicts Emotional intelligence (EI) as a set of cognitive and noncognitive abilities and skills directly and effectively linked to human behaviors in every domain.

Figure 1. Faltas (2017) shows how the cycle of performance, behavior, cognitive and non-cognitive competencies, and the progression of skills and abilities shape EI.

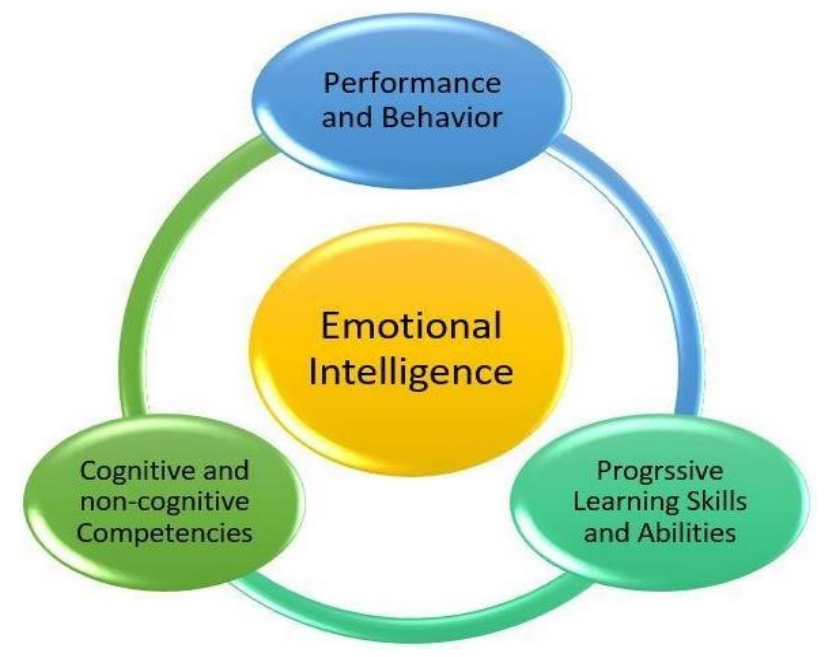

Faltas (2017)

\section{MODELS OF EMOTIONAL INTELLIGENCE}

Emotional intelligence has many different definitions and, hence, uses. Emotional intelligence definitions or models are mostly ability-oriented (ability model) or a mixture of various abilities (mixed model) and personal traits (trait model). The ability-oriented model expresses emotional intelligence as reflecting the competence of comprehending emotional information. Conversely, the mixed models of emotional intelligence link the ability factors with personal characteristics (Mayer, Salovey \& Caruso, 2000).

The starting points are the same when the talent model is compared with the mixed model. Nevertheless, mixed emotional intelligence models are pretty different from the ability models. Although the concept of emotional intelligence includes mental skills in mixed models, it also has elements that define personality traits (Mayer et al., 2000). For this reason, it would be more beneficial to consider the notion of EI within the boundaries of the concept of mental skills and to keep it separate from other personality traits. Thus, it will be possible to analyze the basic dimensions suggested by the talent model of the EI to the people's behavior and success in life. 


\section{a. Ability Model (Salovey \& Mayer, 1997)}

Peter Salovey and John D. Mayer's model of emotional intelligence (Mayer and Salovey, 1997, p. 10-14) has four main branches. The first one is perceiving emotions; it is the ability to realize, decode nonverbal expressions of emotions both in oneself and the others. It also incorporates expressing and making emotional requirements understandable and clear to others. The second branch is taking advantage of emotions to make cognitive activities easier while rationalizing, solving problems, and making decisions. The third branch has to do with emotional understanding; It is the ability to employ emotional knowledge to understand emotions and label emotions properly to interpret their meaning. The last branch is the management of emotions; It is the competence to regulate emotions that contribute to an individual's self-improvement consciously (see also Salovey, Bedell, Detweiler \& Mayer 1999,2000).

The model consists of steps involving the level of abilities to move forward to the next steps subsequently. It is also believed that people with an increased level of Emotional intelligence reach the next steps faster than those experiencing a low level of emotional intelligence. (Mayer \& Salovey, 1997).

\section{b. Goleman's Model of Emotional Intelligence (1998)}

"In a very real sense, we have two minds, one that thinks and one that feels (Goleman 1996)."

Daniel Goleman is a psychologist and science writer who made emotional intelligence more widespread. He discovered the research by Mayer and Salovey, and their findings stimulated his interest and led him to conduct his study on the area and penned the book titled Emotional intelligence (1995). This outstanding book made the concept of EI also known by the public in general. $\mathrm{He}$ describes the idea of emotional intelligence as "the ability to know our emotions as well as others and keep ourselves to be motivated to handle our own emotions and the relationships well (Goleman, 1998). Goleman's model includes five primary emotional intelligence competencies to reach excellent performance: social skill (or relationship management), empathy (or social awareness), selfawareness, motivation, self-regulation (or self-management), and empathy (or social awareness) (Goleman,1998).

The common ground of the various depictions and different models of EI is that it facilitates understanding of our own feelings, positively regulating our emotions, and facilitating relationships. The situation is the same while teaching. Teaching not only involves communicating information to learners but also promotes multilayered personal interaction to accomplish the expected lesson objectives of a given curriculum. Emotional intelligence has various positive impacts on well-being and affects the value of every aspect of life, from job performance to interaction.

\section{c. Bar- On's Mixed Model (1997)}

Reuven Bar-On was concerned with the connection between emotions and social skills. He described EI as "an individual's ability to understand himself and others, establish relationships with people, and adapt to the immediate environment in order to overcome environmental demands successfully." Emotional intelligence components are; general mood, stress management, and personal \& interpersonal adaptability (Bar-On 1997; Stys \& Brown, 2004).

Bar-On (2006) claims that emotional-social intelligence facilitates interdependent emotional and social abilities. It also reflects to what extent an individual can express himself effectively, establish relationships with others, and determine how to cope with other people's daily demands. This model is process-oriented and related to success potential (Bar-On \& Parker, 2000; Bar On, 2002; Stys \& Brown, 2004). Bar-On (2006) stated that the most prominent feature of this model is that it can be taught and learned. Various research has shown that emotional and social intelligence can be enhanced to have positive changes in performance and features such as personal well-being and self- 
actualization (e.g.; Martins, Ramalho, \& Morin, 2010); Schutte, Malouff, Thorsteinsson, Bullar \& Rooke, 2007; Sánchez-Álvarez, Extremera \& Fernández-Berrocal, 2015, 2016).

\section{THE CRITICISMS AGAINST MULTIPLE THEORIES OF EMOTIONAL INTELLIGENCE}

The fact that there are numerous theories regarding emotional intelligence can usually be surprising for people. (e.g., Salovey \& Mayer, 1997; Bar-On, 2000, Goleman, 1995:1998). Every theory has been proposed to understand better and explain the facilities, characteristics, and skills related to social and emotional intelligence. On the other hand, some may argue that with the help of research, "accurate" versions of emotional intelligence have to be named and determined under a single theoretical framework. Though, in another point of view, thanks to the multiple theories in the field, additional attributes of complex psychological constructs can be illustrated. According to a study comparing the EQ-i (Bar-On, 1997) (Reuven Bar-On's model of EQ measurement) with MEIS (Mayer and Salovey's model of EQ measurement), the two measures do not correlate. Even though each theory deviates slightly from its version of the basic meaning of EI), they differ when it comes to their point of view. Emotional intelligence is a relatively 'premature' concept. Thus, as the new scientific data emerges from the research in the field, it is being revealed that there is a connection between emotional intelligence and a variety of traits and abilities that cannot be justified by any other cognitive intelligence types or traditional types of personality measurements.

\section{STRESS, EMOTIONAL INTELLIGENCE \& ENGLISH LANGUAGE TEACHING}

Enduring long-term stress is associated with stress-related disorders subject to the Eleventh Revision of International Classification of Diseases and Related Health Problems (ICD-11) (Keeley, Reed, Roberts, Evans, Robles, Matsumoto, Brewin, Cloitre, Perkonigg, Rousseau, Gureje, Lovell, Sharon, \& Maercker, 2016). It has been correlated with several health problems like anxiety and depression (Fawzy \& Hamed, 2017; Herr, Li, Loerbroks, Angerer, Siegrist, \& Fischer, 2017; Melchior, Caspi, Milne, Danese, Poulton, \& Mof- fitt, 2007; Tennant, 2001), Coronary disease (e.g., Li, Zhang, Loerbroks, Angerer, \& Siegrist, 2014), and sleep problems (e.g., Faber \& Schlarb, 2016).

The fact that teaching is deemed a stressful job should not come as a surprise. Besides, teacher stress has been a phenomenon acknowledged worldwide (Skaalvik \& Skaalvik, 2016). According to a study by Kebede and By Regassa (2014), teaching is one of the most stressful occupations, and 33 to $37 \%$ of teachers are working under tremendous stress because of various types of difficulties that the job has. On the other hand, Abebe and Haile Mariam (2011) argue that stress is the consequence of different intrinsic and extrinsic factors that make the process of adaptation much more complicated and cause teachers to be imbalanced in their personal and professional lives.

The main types of stressors are collected under two headings: personal stressors negatively impact individuals' thinking, beliefs, and internal feelings that make it harder for people to function correctly. On the other hand, situational stressors might occur any time and anywhere, suddenly and unexpectedly. For instance, a teacher might witness some students being subjected to bullying or a fight-individuals' reactions to the stressors, which are the unavoidable reality of life. The reactions to stress change from person to person and situation to situation implies that responses to stress can not be generalized or universalized (Xin, Wu, Yao, Guan, Aleman, \& Luo, 2017).

Various factors such as working in a large and diverse group of students or anticipations of parents and principals are examples of the causes of teacher stress. However, stress is often caused by the constantly changing emotional needs that eventually affect teachers and learners' emotional, social and learning outcomes (Chan, 2006). Likewise, daily duties or workplace-related problems could also be the reason for teacher stress, such as the non-resourceful schools, learners' disinterestedness, colleagues-related or administrational problems. Even the school's environment could be a reason for 
stress, for example, not being able to find a place to live nearby, being subjected to traffic jams, constant noise or weather conditions. (Curry \& O'Brien, 2012).

In addition to the factors mentioned above, emotional energy consumed by interacting with students, administrators, and parents during the day also has a negative impact on teachers' stress levels. (Holmes, 2005). These interactions carry vital importance in making a teacher think that he/she is valued, accepted, supported, or undermined and alone. For this reason, teachers need assistance in developing their self-regulatory resources for coping and being resilient (Roeser, Schonert-Reichl, Jha, Cullen, Wallace, Wilensky \& Harrison, 2013).

According to Ignat and Clipa (2010), being emotionally and professionally competent can help them overcome their problems more efficiently. Emotional intelligence can come in handy while handling their emotions and facing daily struggles that make them emotionally imbalanced. Moreover, Beilock and Ramirez (2011) revealed that comprehending students' emotions in the classroom may lead to a better understanding of their learning styles.

Mayuran (2013) carried out a study aiming to examine the relationship between emotional intelligence and stress management in the school context and banks in Jaffna, showing that emotional intelligence has a moderate and positive impact on stress management. In a different study executed by Punia, Balda, and Poonam (2016), in Haryana, India, Punia, Balda, and Poonam (2016), teachers who have high levels of emotional intelligence are impacted by work-related stress to a low extent. Having a high level of emotional intelligence helps individuals suffer fewer health problems and experience a low level of job-related stress. Emotional intelligence is like a shield protecting individuals from mental health disorders and physical problems (Oginska-Bulik, 2005; Slaski \& Cartwright, 2000).

Emotional intelligence also provides flexibility. Studies put forward that people experiencing a high level of emotional intelligence can handle stressors resulting from adversities faced in any area of life accordingly and flexibly(Zeidner, Matthews \& Roberts, 2012). People experiencing a higher level of emotional intelligence have a can-do attitude facilitating the adaptation processes requiring changes in a stressful situation. They take the changes requiring adaptation as a challenge more than a threat (Schneider, Lyons \& Khazon, 2013).

Armstrong, Galligan, and Critchley (2011) also highlight that emotional intelligence is associated with resilience because behaviors being displayed emotionally intelligent enable people to accommodate themselves to stressful circumstances if needs be. Armstrong et al. (2011) made an investigation including 414 respondents from different age groups ranging from 24 to 58 years old aiming to see the relationship between emotional intelligence and resilience showed that people there is a positive link between EI and resilience and also the ones being in the higher level resilience group experiencing a high level of emotional intelligence.

\section{a. Stress from to Burnout and Emotional Intelligence}

Being exposed to a high level of stress may lead to burnout that could threaten people's physiological and psychological well-being, negatively affect the teaching performance and even endanger the educational system as a whole (Kyriacou, 1987; Yong \& Yue, 2007). Thus, it can be induced that teachers might experience a high level of job-related stress and burnout in their teaching career (Schaufeli, \& Leiter, 2001; Laurențiu et al., 2017; Maslach, Schaufeli, \& Leiter, 2001; MéridaLópez \& Extremera, 2017).

Salovey et al. (1999) revealed that people who have the ability to control their emotions feel better than those who are not. Because they "accurately perceive and appraise their emotional states, know know-how when to express their feelings, and can effectively regulate their mood states." 
Namely, all these competencies consolidate the amount of teachers' vulnerability against burnout syndrome. To put it differently, teachers with a high level of emotional intelligence are less affected by burnout syndrome. As Colomeischi (2015, p.1072) states, "a good teachers' emotional intelligence is negatively correlated with teachers' burnout dimensions." So, if teachers have a high level of emotional intelligence, they are less likely to experience burnout.

The findings of a study carried by Schutte et al. (1998) also support the previous paragraph, emotional intelligence links with less impulsivity, less depression, and greater optimism. People with a high level of emotional intelligence can handle stress better because they can use their emotions and behaviors to lower negative feelings. Not surprisingly, emotional intelligence has a reductive effect on job stress and burnout (Gardner, 2006).

\section{HEALTH AND EMOTIONS}

Lately, how emotional reactions and experiences affect physical and psychological health has increased interest (Tsaousis \& Nikolaou, 2002). Salovey and Mayer (1990) and Mayer and Salovey (1995) states that individuals experiencing a high level of emotional intelligence have better psychological and physical well-being.

Goleman(1995), as well as Salovey and Mayer (1990), states that if people experience a high level of emotional intelligence, they will have in turn have a higher level of well-being:

Inattention to the emotional reality of illness neglects a growing body of evidence showing that people's emotional states can sometimes play a significant role in their vulnerability to disease and the course of their recovery. Modern medicine often lacks emotional intelligence. (Goleman, p. 165)

Goleman was not claiming that all sorts of diseases can be treated by having an optimistic point of view or laughing. He claimed that many daily complaints such as anxiety, depression, and extreme mood swings could be improved by contributing to an individual's emotional intelligence quotient.

A study conducted by Tsaousis and Nikolaou (2005) revealed that a high level of emotional intelligence negatively correlates with poor health. Contrary to what is believed by most people, the power of positive thinking has a more substantial impact on people. For instance; In a study focusing on people having spinal injuries leading to paralyzation indicated that those inclining to think positively were able to grow stronger and ended up with a higher level of physical mobility but, those having a low level of optimism getting more ill and stressed in their lives than the people having a high level of optimism (Goleman, 1995).

Moreover, Epel, Woolery, Stoud and Salovey (2002) studied a higher level of emotional intelligence links with better psychophysiological handling when faced with stressors. Mayer, Detweiler, Bedell and Salovey (1999) carried out a study that revealed that individuals who can regulate their emotional states are healthier than the others because they "accurately perceive and appraise their emotional states, know how and when to express their feelings and can effectively regulate their mood states" (p. 161). It can be concluded that emotional intelligence skills can be related to psychological and physical health. (Tsaousis \& Nikolaou, 2005).

\section{JOB SATISFACTION AND EMOTIONAL INTELLIGENCE}

There is a close relationship between emotional intelligence, job satisfaction, and job success(Goleman, 1998). According to (Bar-on 1997), emotional intelligence is defined as the ability to empathize and understand others and adapt and handle whatever condition requires an individual to achieve his/her desired goal. (Bar-On) states that emotional intelligence helps predict job success because it indicates how an individual takes advantage of his/her emotional knowledge in an urgent situation. Goleman puts forward that (1995) IQ should not be considered a single important factor impacting a person whether he/she will be successful. He argues that emotional intelligence has a vital 
place in people's personal and professional lives. Emotional intelligence takes social intelligence as a base. According to Thorndike (1920) social intelligence is the "ability to understand and manage men and women, boys and girls to act wisely in human relations" (Thorndike, 1920, p. 13). Intrapersonal and interpersonal intelligence types can be counted as the subcategories of social intelligence. Interpersonal intelligence is considered an ability to understand people and factors keeping them motivated and contributing to work cooperatively. Intrapersonal ability helps an individual to know himself/herself accurately and take advantage of this self-knowledge to operate in life as effectively as possible. (Gardner, 1993). p. 10).

\section{JOB PERFORMANCE AND EMOTIONAL INTELLIGENCE}

Specific dimensions of emotional intelligence have been unfolded that contribute to the teaching role (Corcoran \& Tormey, 2012). Teachers who can evaluate their emotions are better while communicating their needs. They also pay more attention to their own feelings to reach their desired goals and improve their performance (George, 2000). Teachers who can appreciate their learners' emotions are more careful to their learners' needs. These teachers tend to back others up emotionally to work with them cooperatively with a common objective. (Day \& Carroll, 2004).

Teaching is a profession surrounded by ever-changing emotions (Erb, 2000), and these emotions can be pretty influential while performing various tasks requiring cognitive processes to reason. Teachers knowing how to take advantage of emotions make cognitive processing easier and contribute to their performance (O'Boyle et al., 2011). Lastly, having the ability to regulate emotions links with emotional self-control. Those teachers having such ability express more suitable emotions when emotionally arousing situations occur and gain more support from their colleagues and principals that positively impact their job outcomes(Brackett et al., 2010). So, it can be inferred that emotional intelligence positively correlates with effective teacher performance. That is, the use of emotions provides an individual to perform better is considered as an ability to make use of emotions to achieve

It is generally accepted that emotional intelligence is essential throughout their teaching career. Teachers having high emotional intelligence are more aware of their emotions; what is more, emotionally intelligent teachers' have more self-confidence, teach efficiently and show determination while setting any goal to reach better personal performance and behaviors (Davies et al., 1998; Law, Wong, \& Song, 2004).

Some researchers have described it as teacher characteristics (Anderson, 1991; Strong, Tucker, \& Ward, 2003), while; other researchers mainly focused on the teaching processes or the teaching outcomes (Flander \& Simon, 1969). Teachers need awareness of their feelings, values, and attitudes as teachers and awareness of their behaviors and how other people see them (Palmer, 1998). If teachers get consistent and constructive feedback from their students, colleagues, and school administration, they improve their self-evaluation abilities. People with a high level of emotional intelligence do not have second thoughts to be criticized or ask feedback from the people with whom they work. In the long run, getting constant feedback will help them improve their performance. Teachers experiencing a high level of emotional intelligence are optimistic, adaptable, collaborative, self-confident, authoritative, open, approachable, and willing (Mortiboys, 2005). They are better at communicating, finding solutions to conflicts, (Ming, 2003 ), solving problems, curbing their impulsive behaviors, maintaining their self-control, and having higher self-confidence. If people can keep their motivation at a higher level, it helps them be more assertive and more responsible and deal with the factors causing them to be stressed. (Salami, 2010).

Emotionally intelligent teachers are inclined to have a good command both in their content and the materials they use while teaching. It helps them to be more flexible and ready while teaching. They make efforts to make their materials used as efficiently as possible and ponder about the best method that is more suitable to the topic they cover to meet their learners' needs and expectations(Jensen, 1998). 
In summary, if teachers are emotionally stable, they tend to avoid situations that bring about emotional exhaustion, such as conflicting with others. It also helps them deal with stress and burnout better and perform better (Slaski \& Cartwright, 2002).

\section{EMOTIONAL INTELLIGENCE IN THE FIELD OF ENGLISH LANGUAGE TEACHING}

Three main reasons explain why social and emotional intelligence are essential for contemporary language classrooms. Firstly, there is a tendency to put the communicative language teaching approach in many contemporary language teaching contexts. Activities promoting communicative use of language through peer works, in-classroom discussions, and group activities are favored in a classroom in which communicative language teaching is used as a method. Regarding the Language teachers' making use of activities involving such in-class communication and cooperation, According to Dörnyei and Murphey (2003)," the group dynamics is probably one of the most, if not the most - useful sub-disciplines in the social sciences for language teachers". Modern communicative language teaching methods promote social, interactional, and interpersonal interactions requiring both learners and teachers to have communicative competencies. No matter what methods the teacher utilizes in the classroom, almost all of these methods require social interaction and communication in one way or another and most probably some activities demanding the students to work cooperatively with their peers, all of which can be used by teachers and learners who are emotionally and socially competent.

The second one is related to the language classrooms' multilingual and multicultural aspects. Intercultural competence is considered a need for both English language teachers and learners in such classrooms. In order to develop and maintain good interpersonal relationships with others, especially with the ones from different cultures, being socially and emotionally competent while being caring and empathetic for other people's needs and feelings is a must-have trait not only for language learners but also for teachers (Matsumoto 2007; Spencer- Oatey and Franklin, 2009).

According to Kumaravadivelu (2012), the act of caring in interpersonal relationships "helps us listen attentively to others without prejudice." He also asserts that caring for students' feelings in a multicultural and multilingual classroom is the most crucial thing to do by a teacher. This applies especially to language teachers because they deal with a language of globality and coloniality and face numerous dilemmas and conflicts almost regularly (Kumaravadivelu, 2012). Thus, teachers of English have to be competent in terms of emotional and social intelligence.

The third reason social and emotional intelligence is crucial in language learning is the necessity of intercultural competence for learners and teachers. Intercultural competence refers to being ethnoculturally empathetic to people from other cultures and understanding how they differ from us in terms of world views (Rasoal, Eklund \& Hansen 2011). Promoting empathy for learners is critical in developing their emotional and social intelligence. This way, learners will learn to understand and respect cultural differences and become more open-minded. In English language classrooms, a lingua franca is being taught; thus, learners and teachers of English have to be more empathetic, and the lessons should not be culture-specific (Mercer, 2016).

\section{a) Emotional Intelligence and Language Learners}

Numerous researchers have experimented with the correlation between emotional intelligence and academic achievement. For instance, to evaluate the relationship between emotional intelligence and language achievement on the four main skills, Pishghadam (2009) examined 508 EFL university students. The results showed that language achievement and emotional intelligence are closely associated. Furthermore, MacCann, Fogarty, Zeidner \& Roberts (2011) verified the enormous effect emotional intelligence has on the academic success of 452 students. Mohammadi (2012) analyzed 191 students in other research to determine whether English language learning and emotional intelligence are linked. The results revealed that they are profoundly relevant. In another study by Dastgoshadeh \& Javanmardi (2021), the correlation between emotional intelligence and language learners' willingness to communicate was examined, and results showed a positive correlation between the two variables. 
Contrarily, some research did not find any correlation between emotional intelligence and language achievement. For example, in a study examining 180 language learners, Newsome, Day \& Catano (2000) found no substantial effect of emotional intelligence on their language achievement. Moreover, a study examining the academic achievement of 187 language learners by Meshkat (2011) showed no advantage of emotional intelligence. Examining the potential impacts of emotional intelligence on 65 students' language learning, Khalili (2013) could not determine a relationship between the two variables. The research mentioned above revealed that language learners' level of emotional intelligence is not consistently impactful.

\section{b) Emotional Intelligence and Language Teachers}

Being aware of their own emotions and the concept of emotional intelligence would be beneficial for teachers and students. EI encourages language learning in various aspects and enhances language retention. In addition, it is argued that EI can fill the gaps occurring during students' language acquisition process, which impede the actual application of the information they have. As a result, language teaching can be carried out more efficiently.

In a study conducted by Moafian and Ghanizadeh (2009), the relationship between Iranian EFL teachers' EI and their sense of efficacy in language teaching has been investigated. The study results indicated that a significant positive relationship exists between EI and teaching efficacy. Moreover, a high level of emotional intelligence was associated with enhanced level of teacher selfefficacy (Ghanizadeh and Moafian, 2009) and enhanced emotion regulation skills during instruction (Gregersen, MacIntyre \& Meza, 2014). In addition, intriguing results arose from a recent project investigating English teachers' emotional and social intelligence (see Gkonou and Mercer 2017). The project revealed that English teachers reported high levels of emotional intelligence and that variables of gender and years of teaching experience were critical forecasters of emotional intelligence.The project also revealed that emotionally intelligent language teachers tend to be more diverse and take advantage of their past experiences while dealing with contemporary problems. The intuitive knowledge they gained through long and varied teaching experiences shaped their EI and was activated when they needed to make emotional decisions in the classroom.

In a study Dewaele and Mercer (2017) evaluated the differences in self-reported attitudes of 513 English teachers towards their students. The researchers found that teachers with high levels of emotional intelligence have more positive attitudes towards their students and enjoy interacting with students more; while teachers with low emotional intelligence may find the teaching profession particularly challenging.

\section{RECOMMENDATIONS \& CONCLUSION}

Consequently, many researchers have hypothesized that being emotionally intelligent can lead to emotional well-being (Goleman,1995; Saarni, 1999; Salovey \& Mayer,1990; Salovey, Mayer, Goldman, Turvey, \& Palfai, 1995). Those capable of knowing and controlling their emotions would have a healthier outlook on life and better emotional health. Research suggests that higher emotional intelligence is correlated with lower depression (Martinez-Pons, 1997; Schutte et al ., 1998), higher happiness (Schutte et al., 1998), and greater satisfaction with life (Ciarrochi et al., 2000; MartinezPons, 1997). Thus, both theory and previous research indicate a connection between emotional intelligence and emotional well-being. It can be clearly understood that emotional intelligence plays a crucial role in having better well-being.

For the sake of English language learning and teaching, emotional intelligence can be developed through activities that encourage sharing opinions and communication in the language classroom. A variety of methods and approaches appropriate for different learning styles should be included in the curriculum so that the students can maintain interest in the lesson and enhance their emotional intelligence.Ice-breaking activities, for instance, may encourage students to get to know each other and develop an interest in lessons related to the topic area. 
Providing efficient language teaching to students requires being emotionally competent, in other words, developing emotional intelligence; though, students need to be provided with methods and techniques so that meaningful communication as peers or as a group can exist. The students also need a positive classroom environment in which they can boost their self-esteem and work with their peers cooperatively. Reflective language learning is effective because it supports learners to talk about their feelings. Moreover, it can make the language more pleasant and remarkable.

\section{REFERENCES}

Abebe, S., \& HaileMariam, A. (2011). Teacher stressors and potential remedies from pre-service teachers' and cooperating teachers. Eastern Education Journal, 40(1), 64-74.

Alemu, Y., Teshome, A., Kebede, M., \& Regassa, T. (2014). Experience of stress among studentteachers enrolled in postgraduate diploma in teaching (PGDT): The case of Haramaya University cluster centers, Ethiopia. African Educational Research Journal, 2(3), 96-101.

Anderson, L. W. (1991). Increasing teacher effectiveness, fundamentals of educational planning. Paris: international institute for educational planning UNESCO.

Armstrong, A. R., Galligan, R. F., \& Critchley, C. R. (2011). Emotional intelligence and psychological resilience to negative life events. Personality and Individual Differences, 51(3), 331-336.

Baron, R. (1997). The BarOn emotional quotient inventory (BarOn EQ-i). Toronto, ON: Multi-Health Systems Inc.

Bar-On, R. (2002). Emotional quotient inventory-Short form. PsycTESTS Dataset. doi:10.1037/t03760-000

Bar-On, R. (2006). The Bar-On model of emotional-social intelligence (ESI) 1. Psicothema, 13-25.

Bar-On, R. E., \& Parker, J. D. (2000). The handbook of emotional intelligence: theory, development, assessment, and application at home, school, and in the workplace. Jossey-Bass.

Beilock, S. L., \& Ramirez, G. (2011). On the interplay of emotion and cognitive control: Implications for enhancing academic achievement. In Psychology of learning and motivation, 55, 137-169. Academic Press.

Brackett, M. A., Palomera, R., Mojsa- Kaja, J., Reyes, M. R., \& Salovey, P. (2010). Emotionregulation ability, burnout, and job satisfaction among British secondary- school teachers. Psychology in the Schools, 47(4), 406-417.

Chan, D. W. (2006). Emotional intelligence and components of burnout among Chinese secondary school teachers in Hong Kong. Teaching and Teacher Education, 22(8), 1042-1054. doi:10.1016/j.tate.2006.04.005

Ciarrochi, J. V., Chan, A. Y., \& Caputi, P. (2000). A critical evaluation of the emotional intelligence construct. Personality and Individual differences, 28(3), 539-561.

Colomeischi, A. A. (2015). Teachers burnout in relation with their emotional intelligence and personality traits. Procedia - Social and Behavioral Sciences, 180, 1067-1073. doi:10.1016/j.sbspro.2015.02.207

Corcoran, R. P., \& Tormey, R. (2012). How emotionally intelligent are pre-service teachers?. Teaching and Teacher Education, 28(5), 750-759.

Curry, J. R., \& O'Brien, E. R. (2012). Shifting to a wellness paradigm in teacher education: A promising practice for fostering teacher stress reduction, burnout resilience, and promoting retention. Ethical Human Psychology and Psychiatry, 14(3), 178-191.

Dastgoshadeh, A., \& Javanmardi, P. (2021). Emotional Intelligence as a Predictor of EFL Learners' Willingness to Communicate. MEXTESOL Journal, 45(3), n3.

Davies, M., Stankov, L., \& Roberts, R. D. (1998). Emotional intelligence: in search of an elusive construct. Journal of personality and social psychology, 75(4), 989.

Day, A. L., \& Carroll, S. A. (2004). Using an ability-based measure of emotional intelligence to predict individual performance, group performance, and group citizenship behaviours. Personality and Individual differences, 36(6), 1443-1458.

Dewaele, J. M., \& Dewaele, L. (2017). The dynamic interactions in foreign language classroom anxiety and foreign language enjoyment of pupils aged 12 to 18. A pseudo-longitudinal investigation. Journal of the European Second Language Association, 1(1). 
Mert Pekbay, Onur Karasu, Oya Tunaboylu

Dörnyei, Z., \& Murphey, T. (2003). Group dynamics in the language classroom. Ernst Klett Sprachen.

Erb, C. S. (2002, May). The emotional whirlpool of beginning teachers' work. In annual meeting of the Canadian Society of Studies in Education, Toronto, Canada.

Faber, J., \& Schlarb, A. A. (2016). The Relation of Sleep, Distress, and Coping Strategies-What Male and Female Students Can Learn from Each Other?. Health, 8(13), 1356.

Faltas, I. M. (2018). Effect of administrative practices on law enforcement officers' emotional intelligence and behavior (Doctoral dissertation, Walden University).

Fawzy, M., \& Hamed, S. A. (2017). Prevalence of psychological stress, depression and anxiety among medical students in Egypt. Psychiatry research, 255, 186-194.

Fernández-Berrocal, P., \& Extremera, N. (2006). Emotional intelligence: A theoretical and empirical review of its first 15 years of history. Psicothema, 18, 7-12.

Flanders, N. A., \& Simon, A. (1969). Teacher effectiveness. Classroom Interaction Newsletter, 5(1), 18-37.

Gardner, H. (1993). Multiple intelligences: The theory in practice. Basic books.

Gardner, L. (2006). Emotional Intelligence and Occupational Stress.

George, J. M. (2000). Emotions and leadership: The role of emotional leadership. Human Relations, 53(8), 1027-1055.

Gkonou, C., \& Mercer, S. (2017). Understanding emotional and social intelligence among English language teachers. British Council.

Gardner, H. E. (1993). Multiple intelligences: The theory in practice, a reader. Basic Books.

Goleman, D. (1995). Emotional intelligence. Bantam.

Goleman, D. (1998). Working with emotional intelligence. Bantam.

Goleman, D., \& Griese, F. (1996). Emotionale intelligenz. Hanser.

Greenspan, S. I., \& Pollock, G. H. (1980). The Course of life : psychoanalytic contributions toward understanding personality development (1st ed.). Washington.

Gregersen, T., MacIntyre, P. D., \& Meza, M. D. (2014). The motion of emotion: Idiodynamic case studies of learners' foreign language anxiety. The Modern Language Journal, 98(2), 574-588.

Harter, J. K., Schmidt, F. L., \& Hayes, T. L. (2002). Business-unit-level relationship between employee satisfaction, employee engagement, and business outcomes: A metaanalysis. Journal of Applied Psychology, 87(2), 268-279. doi:10.1037/0021-9010.87.2.268

Herr, R. M., Li, J., Loerbroks, A., Angerer, P., Siegrist, J., \& Fischer, J. E. (2017). Effects and mediators of psychosocial work characteristics on somatic symptoms six years later: Prospective findings from the Mannheim Industrial Cohort Studies (MICS). Journal of psychosomatic research, 98, 27-33.

Hockenbury, D. H., \& Hockenbury, S. E. (2007). Discovering psychology (4th ed.). Worth Publishers.

Holmes, E. (2005). Teacher well-being: Looking after yourself and your career in the classroom. Routledge.

Ignat, A. A., \& Clipa, O. (2010). The Impact of Self-Efficacy and Locus of Control on the Professional Development of the Teachers. Petroleum-Gas University of Ploiesti Bulletin, Educational Sciences Series, 62.

Jensen, E. (Ed.). (2008). Super teaching: Over 1000 practical strategies. Corwin press.

Keeley, J. W., Reed, G. M., Roberts, M. C., Evans, S. C., Medina-Mora, M. E., Robles, R., ... \& Saxena, S. (2016). Developing a science of clinical utility in diagnostic classification systems: Field study strategies for ICD-11 mental and behavioral disorders. American Psychologist, $71(1), 3$.

Khalili, M. A. (2013). Relationship between emotional intelligence \& leadership style human resources management. International Journal of Management Research and Reviews, 3(4), 2689.

Kumaravadivelu, B. (2012). Language teacher education for a global society: A modular model for knowing, analyzing, recognizing, doing, and seeing. Routledge.

Kyriacou, C. (1987). Teacher stress and burnout: An international review. Educational research, 29(2), 146-152.

Law, K. S., Wong, C. S., \& Song, L. J. (2004). The construct and criterion validity of emotional intelligence and its potential utility for management studies. Journal of applied Psychology, 89(3), 483. 
Lee, F. M. E. (2003). Conflict management styles and emotional intelligence of faculty and staff at a selected college in southern Taiwan. University of South Dakota.

Li, J., Zhang, M., Loerbroks, A., Angerer, P., \& Siegrist, J. (2014). Work stress and the risk of recurrent coronary heart disease events: A systematic review and meta-analysis. International journal of occupational medicine and environmental health, 1-12.

MacCann, C., Fogarty, G. J., Zeidner, M., \& Roberts, R. D. (2011). Coping mediates the relationship between emotional intelligence (EI) and academic achievement. Contemporary educational psychology, 36(1), 60-70.

Maricuțoiu, L. P., Sulea, C., \& Iancu, A. (2017). Work engagement or burnout: Which comes first? A meta-analysis of longitudinal evidence. Burnout research, 5, 35-43.

Martinez-Pons, M. (1997). The relation of emotional intelligence with selected areas of personal functioning. Imagination, cognition and personality, 17(1), 3-13.

Martins, A., Ramalho, N., \& Morin, E. (2010). A comprehensive meta-analysis of the relationship between emotional intelligence and health. Personality and individual differences, 49(6), 554564.

Maslach, C., Schaufeli, W. B., \& Leiter, M. P. (2001). Job burnout. Annual review of psychology, 52(1), 397-422.

Matsumoto, D. (2007). Culture, context, and behavior. Journal of personality, 75(6), 1285-1320.

Matzel, L. D., \& Sauce, B. (2017). Department of Psychology, Rutgers University, Piscataway, NJ, USA.

Mayer, J. D., Salovey, P., \& Caruso, D. R. (2000). Emotional intelligence as zeitgeist, as personality, and as a mental ability.

Mayuran, L. (2013). Impact of emotional intelligence on stress management: Study of Schools with Banks in Jaffna District. Global Journal of Commerce \& Management Perspective, 2(6), 6771.

Melchior, M., Caspi, A., \& Milne, B. J., Danese, A., Poluton, R., \& Moffitt, T, R.(2007). Work stress precipitates depression and anxiety in young, working women and men. Psychological Medicine, 37(8), 1119-1129.

Mercer, S., Oberdorfer, P., \& Saleem, M. (2016). Helping language teachers to thrive: Using positive psychology to promote teachers' professional well-being. In Positive psychology perspectives on foreign language learning and teaching, 213-229.

Mérida-López, S., \& Extremera, N. (2017). Emotional intelligence and teacher burnout: A systematic review. International Journal of Educational Research, 85, 121-130.

Meshkat, M. (2011). The relationship between emotional intelligence and academic success.

Moafian, F., \& Ghanizadeh, A. (2009). The relationship between Iranian EFL teachers' emotional intelligence and their self-efficacy in Language Institutes. System, 37(4), 708-718.

Mohammadi, M. (2012). The role of emotional intelligence on English learning as a second language. International Research Journal of Applied and Basic Sciences, 3(9), 1953-1956.

Mortiboys, A. (2013). Teaching with emotional intelligence: A step-by-step guide for higher and further education professionals. Routledge.

Newsome, S., Day, A. L., \& Catano, V. M. (2000). Assessing the predictive validity of emotional intelligence. Personality and Individual differences, 29(6), 1005-1016.

Nikolaou, I., \& Tsaousis, I. (2002). Emotional intelligence in the workplace: Exploring its effects on occupational stress and organizational commitment. The International Journal of Organizational Analysis.

O'Boyle Jr, E. H., Humphrey, R. H., Pollack, J. M., Hawver, T. H., \& Story, P. A. (2011). The relation between emotional intelligence and job performance: A meta- analysis. Journal of Organizational Behavior, 32(5), 788-818.

Oginska-Bulik, N. (2005). Emotional intelligence in the workplace: Exploring its effects on occupational stress and health outcomes in human service workers. International journal of occupational medicine and environmental health, 18(2), 167-175.

Palmer, P. J. (1998). The Courage to Teach. San Francisco.

Pishghadam, R., Askarzadeh Torghabeh, R., \& Navari, S. (2009). Metaphor analysis of teachers' beliefs and conceptions of language teaching and learning in Iranian high schools and language institutes: A qualitative study. Iranian EFL Journal, 4. 
Mert Pekbay, Onur Karasu, Oya Tunaboylu

Punia, N. (2016). Stress, Professional Burnout and Emotional Intelligence of School Teachers in Haryana (Unpublished doctoral dissertation).

Rasoal, C., Eklund, J., \& Hansen, E. M. (2011). Toward a conceptualization of ethnocultural empathy. Journal of Social, Evolutionary, and Cultural Psychology, 5(1), 1.

Roeser, R. W., Schonert-Reichl, K. A., Jha, A., Cullen, M., Wallace, L., Wilensky, R., ... \& Harrison, J. (2013). Mindfulness training and reductions in teacher stress and burnout: Results from two randomized, waitlist-control field trials. Journal of educational psychology, 105(3), 787.

Saarni, C. (1999). The development of emotional competence. Guilford press.

Saint-Exupéry, A. D. (2019). El Principito: The little prince. Editorial Verbum.

Salami, S. O. (2010). Occupational Stress and Well-Being: Emotional Intelligence, Self-Efficacy, Coping, Negative Affectivity And Social Support As Moderators. Journal of International Social Research, 3(12).

Salovey, P. E., \& Sluyter, D. J. (1997). Emotional development and emotional intelligence: Educational implications. Basic Books.

Salovey, P., \& Mayer, J. D. (1990). Emotional intelligence. Imagination, cognition and personality, 9(3), 185-211.

Salovey, P., Bedell, B. T., Detweiler, J. B., \& Mayer, J. D. (1999). Coping intelligently. Coping: The psychology of what works, 141-164.

Salovey, P., Bedell, B. T., Detweiler, J. B., \& Mayer, J. D. (2000). Current directions in emotional intelligence research.

Salovey, P., Mayer, J. D., Goldman, S. L., Turvey, C., \& Palfai, T. P. (1995). Emotional attention, clarity, and repair: Exploring emotional intelligence using the Trait Meta-Mood Scale. In J. W. Pennebaker (Ed.), Emotion, disclosure, \& health (pp. 125-154). American Psychological Association. https://doi.org/10.1037/10182-006

Salovey, P., Stroud, L. R., Woolery, A., \& Epel, E. S. (2002). Perceived emotional intelligence, stress reactivity, and symptom reports: Further explorations using the trait meta-mood scale. Psychology and health, 17(5), 611-627.

Sánchez-Álvarez, N., Extremera, N., \& Fernández-Berrocal, P. (2016). The relation between emotional intelligence and subjective well-being: A meta-analytic investigation. The Journal of Positive Psychology, 11(3), 276-285.

Schneider, T. R., Lyons, J. B., \& Khazon, S. (2013). Emotional intelligence and resilience. Personality and Individual Differences, 55(8), 909-914.

Schutte, N. S., Malouff, J. M., Hall, L. E., Haggerty, D. J., Cooper, J. T., Golden, C. J., \& Dornheim, L. (1998). Development and validation of a measure of emotional intelligence. Personality and individual differences, 25(2), 167-177.

Schutte, N. S., Malouff, J. M., Thorsteinsson, E. B., Bhullar, N., \& Rooke, S. E. (2007). A metaanalytic investigation of the relationship between emotional intelligence and health. Personality and individual differences, 42(6), 921-933.

Skaalvik, E. M., \& Skaalvik, S. (2016). Teacher stress and teacher self-efficacy as predictors of engagement, emotional exhaustion, and motivation to leave the teaching profession. Creative Education, 7(13), 1785.

Slaski, M., \& Cartwright, S. (2000). Emotional Intelligence Training and its Implications for Stress. In Health and Performance Based on paper presented at 3rd World Congress on Stress, September (pp. 24-27).

Slaski, M., \& Cartwright, S. (2002). Health, performance and emotional intelligence: An exploratory study of retail managers. Stress and Health: Journal of the International Society for the Investigation of Stress, 18(2), 63-68.

Spencer-Oatey, H., \& Franklin, P. (2009). Intercultural interaction: A multidisciplinary approach to intercultural communication. Springer.

Strong, J. H., Tucker, P. D., \& Ward, T. J. (2003). Tennessee Value Added Assessment System (TV AAS) database: Implications for educational evaluation and research. Journal of Personnel Evaluation in Education, 12(3), 247-256.

Stys, Y., \& Brown, S. L. (2004). A review of the emotional intelligence literature and implications for corrections. 
Tennant, C. (2001). Work-related stress and depressive disorders. Journal of psychosomatic research, 51(5), 697-704.

Thorndike, E. L. (1920). Intelligence and its uses. Harper's magazine.

Tsaousis, I., \& Nikolaou, I. (2005). Exploring the relationship of emotional intelligence with physical and psychological health functioning. Stress and Health: Journal of the International Society for the Investigation of Stress, 21(2), 77-86.

Xin, Y., Wu, J., Yao, Z., Guan, Q., Aleman, A., \& Luo, Y. (2017). The relationship between personality and the response to acute psychological stress. Scientific reports, 7(1), 1-8.

Yong, Z., \& Yue, Y. (2007). Causes for burnout among secondary and elementary school teachers and preventive strategies. Chinese Education \& Society, 40(5), 78-85.

Zeidner, M., Matthews, G., \& Roberts, R. D. (2012). The emotional intelligence, health, and wellbeing nexus: What have we learned and what have we missed?. Applied Psychology: Health and Well-Being, 4(1), 1-30. 